\title{
Fibrinopeptide A Induces Expression of C-Reactive Protein via the ROS-ERK1/2/ P38-NF-kB Signal Pathway in Vascular Smooth Muscle Cells
}

\author{
Shouzhu Xua Jing Zhao Juntian Liüa Wei Gou \\ aDepartment of Pharmacology, Xi'an Jiaotong University School of Medicine, Xi'an, 'bey Laboratory of \\ Environment and Genes Related to Diseases (Xi'an Jiaotong University), Ministry of Education, Xi'an, \\ China
}

\section{Key Words}

Fibrinopeptide A $\cdot \mathrm{CRP} \cdot$ Vascular smooth muscle cells $\cdot$ Inflammation $\cdot$ Atherosclerosis

\begin{abstract}
Background/Aims: Atherosclerosis is a chronic inflammatory disease in the artery walls. Fibrinopeptide A (FPA) is a biomarker of the activation of coagulation system, and a high concentration of FPA in blood occurs in patients with ischemic heart disease etc. However, there exist few studies on the pathological effects of FPA in cardiovascular system. Therefore, the present study examined the effect of FPA on CRP expression in VSMCs and the molecular mechanisms. Methods: mRNA and protein expression was identified by quantitative real-time PCR and Western blot, respectively. Reactive oxygen species (ROS) and the immunofluorescence staining were observed by a fluorescence microscope. Plasma FPA and CRP level was determined by ELISA. Results: FPA induced the expressions of CRP, IL-1 $\beta$ and IL- 6 in VSMCs, and anti-IL-1 $\beta$ and anti-IL- 6 neutralizing antibodies partially reduced FPAinduced CRP expression in VSMCs. The subchronic administration of FPA to rats increased FPA level in plasma and CRP expression in the aortic artery walls. The further studies showed that FPA promoted superoxide anion generation in VSMCs. Antioxidant NAC antagonized FPA-stimulated superoxide anion generation and inhibited FPA-induced CRP expression in VSMCs. FPA activated ERK1/2 and p38 phosphorylation, and PD98059 and SB203580 reduced FPA-induced CRP expression. Moreover, NAC inhibited the activation of ERK1/2 and p38. In addition, FPA enhanced NF-KB level in the nuclei of VSMCs, and PDTC reduced FPA-induced expression of CRP. Conclusions: FPA induces CRP expression in VSMCs via ROS-ERK1/2/p38NF- $\mathrm{B}$ s signal pathway. This finding for the first time provides an experimental evidence for pro-inflammatory effect of FPA.

S. Xu and J. Zhao contributed equally to this work. 


\section{Cellular Physiology Cell Physiol Biochem 2018;47:266-278 \begin{tabular}{l|l} 
DOI: 10.1159/000489805 & and Biochemistry \\
Published online: May 17, 2018 & $\begin{array}{l}\text { 2018 The Author(s). Published by S. Karger AG, Basel } \\
\text { www.karger.com/cpb }\end{array}$
\end{tabular} $\mathrm{Xu}$ et al.: FPA Induces CRP Expression in VSMCs}

\section{Introduction}

Atherosclerosis is a disease associated with chronic inflammation in the artery wall and inflammation is involved in the different phases of the disease from the plaque formation to the plaque rupture [1,2]. Data from the clinical and experimental researches show that inflammatory markers like cytokines, acute-phase response proteins and cellular adhesion molecules are able to predict the event of atherosclerosis [3]. As an acute-phase response protein, $\mathrm{C}$-reactive protein (CRP) is considered as an independent risk factor of atherosclerosis. CRP is not only a predictor of atherosclerosis but also plays a pivotal role in the progression of atherosclerosis [4]. CRP regulates the activities and expressions of many factors participating in atherogenesis [5], such as evoking interleukin- 6 and endothelin-1 releases [6], inducing the expressions of adhesion molecules and monocyte chemoattractant protein-1 (MCP-1) [7]; promoting the uptake of low-density lipoprotein by macrophage and stimulating the migration and proliferation of vascular smooth muscle cells (VSMCs) [8].

VSMCs are involved in the whole progress of atherosclerosis, especially in the plaque formation [9-12]. Although the circulating CRP is mainly from hepatocytes and nonhepatocytes including neurons, renal epithelium and respiratory tract, a growing evidence has identified that VSMCs also produce CRP $[13,14]$. Moreover, the locally produced CRP in the vessel wall may play a direct and key role in the progress of atherosclerosis and cardiovascular complications.

The earlier studies showed that fibrinogen and its degradation products are involved in the development of atherosclerosis by mediating inflammatory responses and participating in thrombosis formation [15-19]. Fibrinopeptide A (FPA) is a peptide of 16 amino acids which occurs as a natural consequence of hemostasis from proteolysis of fibrinogen's $A \alpha$ chain [20]. The peptide exists in blood of normal healthy individuals at the concentration of 0.5-2.0 nM, and is 2-10 time higher in blood of the patients with thrombotic disease, pulmonary embolism and acute ischemic cardiovascular disease [21-26]. Surprisingly, so far there have been few studies on the biological activity of FPA. The limited reports show that FPA causes an irreversible damage to endothelial cells [27], stimulates the secretions of IL-8, MCP-1, macrophage migration inhibitory factor and serpin E1 in dermal microvascular endothelial cells [28]; promotes an infiltration of leukocytes and the production of the proinflammatory cytokine MCP-1 in the inflammation site after the injection into BALB/C mice [29]. In the present research, we examined the effect of FPA on CRP expression in VSMCs and probed whether reactive oxygen species (ROS), mitogen-activated protein kinase (MAPK) and nuclear factor kappa B (NF-KB) signal pathway played a role in FPA-induced CRP expression.

\section{Materials and Methods}

\section{Reagents}

Dulbecco's High Glucose Modified Eagles Medium (DMEM) and fetal bovine serum (FBS) were purchased from Gibco BRL (Grand Island, NY, USA). FPA, PD98059, SB203580, SP600125, N-acetylcysteine (NAC), pyrrolidine dithiocarbamate (PDTC), thenoyltrifluoroacetone (TTFA) and diphenyleneiodonium (DPI) were from Sigma-Aldrich (St. Louis, MO, USA). Rabbit polyclonal CRP antibody and mouse $\alpha$-smooth muscle actin antibody were provided by Abcam (Cambridge, MA, USA). Rabbit monoclonal $\beta$-actin antibody was ordered from Zhuangzhi Biotech (Xi'an, China). NF- $\kappa B$ activation and nuclear translocation kits, 2',7'-dichlorodihydrofluororescein diacetate (H $\left.\mathrm{H}_{2} \mathrm{DCF}-\mathrm{DA}\right)$, ERK1/2 and phospho-ERK1/2 antibodies were obtained from Beyotime (Jiangsu, China). Phospho-p38 and p38 antibody were from Cell Signaling Technology (Danvers, MA, USA). Relative second antibodies were provided by CW Biotech (Beijing, China). Rabbit monoclonal lamin B1 antibody was from Abnova (Taipei, Taiwan, China). Anti-rat IL1 $\beta$ and anti-rat IL-6 neutralizing antibodies were ordered from R\&D Systems (MN, USA). ELISA kits for detecting IL-1 $\beta$ and IL-6, and for assay of FPA were from West Tang (Shanghai, China) and MLBIO Biotech (Shanghai, China) respectively. 


\section{Cellular Physiology Cell Physiol Biochem 2018;47:266-278 and Biochemistry Published online: May 17, $2018 \quad$\begin{tabular}{l|l} 
DOI: 10.1159/000489805 2018 The Author(s). Published by S. Karger AG, Basel \\
www.karger.com/cpb
\end{tabular} $\mathrm{Xu}$ et al.: FPA Induces CRP Expression in VSMCs}

\section{Culture of rat VSMCS}

The primary VSMCs separated from the thoracic aorta of male Sprague Dawley (SD) rats were cultured in DMEM supplemented with $10 \% \mathrm{FBS}, 100 \mathrm{U} / \mathrm{ml}$ penicillin and $100 \mathrm{U} / \mathrm{ml}$ streptomycin at $37^{\circ} \mathrm{C}$ in a $5 \% \mathrm{CO}_{2}$ incubator as previously described $[30,31]$. The cells showed the typical "hill and valley" morphology and 99\% purity as identified by the immunofluorescence staining with $\alpha$-smooth muscle-actin antibody (showed in Fig 1). The cells between passages 3 and 8 were used in the present study. The cells were incubated in the serum-free medium for an additional $12 \mathrm{~h}$ before the experiments. All experimental procedures were strictly performed according to the international, national and institutional rulers, and approved by the Institutional Animal Care Committee of Xi'an Jiaotong University.

\section{Assessment of the viability of VSMCs by the MTT methods.}

VSMCs were incubated with $10^{-4}-1.0 \mu \mathrm{M}$ FPA for $12 \mathrm{~h}$ or with $10^{-2} \mu \mathrm{M}$ FPA for $0-24 \mathrm{~h}$. Then, $20 \mu \mathrm{l}$ MTT ( $5 \mathrm{mg} / \mathrm{ml}$, Invitrogen, Carlsbad, CA, USA) was added to each well. After the incubation at $37^{\circ} \mathrm{C}$ for $4 \mathrm{~h}$, the culture medium was carefully removed and the formed formazan crystal was dissolved in $150 \mu \mathrm{l}$ DMSO (Sigma-Aldrich, St. Louis, MO, USA) with vigorous shaking for $10 \mathrm{~min}$. Finally, the optical density was determined at $490 \mathrm{~nm}$ with micro-plate reader (Bio-Rad, Hercules, CA, USA).

\section{Quantitative real-time PCR}

Total RNA was extracted from VSMCs using RNAfast100 purification kit (Xianfeng Biotech, Shaanxi, China). Complementary DNA (cDNA) was synthesized from total RNA ( $2 \mu \mathrm{g}$ ) by Revert Aid ${ }^{\mathrm{TM}}$ First Strand cDNA synthesis kit (TaKaRa, Tokyo, Japan) in accordance with the method provided by the manufacturer. Amplification of cDNA was accomplished by primer pairs specific for rat (showed in Table 1). Quantitative real-time PCR was performed using Agilent MX3000 Real-Time PCR System (Santa Clara, CA, USA). The reaction products were measured by detecting the binding of SYBR Green I to DNA using SYBR Green PCR Master Mix (Roche, Basel, Switzerland). Optimization of the amplification reaction was assured by a dissociation curve analysis. All samples were run in triplicate, and then analyzed using the $2^{-\Delta \Delta \mathrm{Ct}}$ methods. The level of mRNA was expressed as relative to internal control GAPDH.

\section{Western blot}

VSMCs were washed 3 times with the ice-cold PBS after the treatments. The whole cell lysates were acquired using the lysis buffer supplemented with protease inhibitor cocktail and phosphatase inhibitors (Roche, Basel, Switzerland). Concentration of the protein was measured by BCA protein assay kit (Bio-Rad, Hercules, CA, USA). Equal amount of the protein $(40 \mu \mathrm{g})$ was loaded, separated by $10 \%$ SDS-PAGE, and blotted onto PVDF membrane $(0.45 \mu \mathrm{m}$, GE Healthcare, Buckinghamshire, UK). The membranes were incubated with anti-CRP (1:800 dilution), anti- $\beta$-actin (1:2000 dilu-

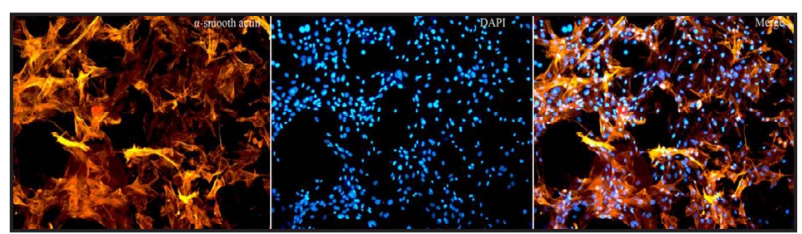

Fig. 1. Characterization of the primary cultured VSMCs derived from the thoracic aorta of male Sprague-Dawley rats. The cells were stained with $\alpha$-smooth muscle actin antibody and labeled with the cy3 conjugated antibody (left), with DAPI (middle) and the merged field of red and purple color (right). The cells were observed at magnification of $200 \times$ under a fluorescence microscope.

Table 1. Primers used for quantitative real-time PCR

\begin{tabular}{lccc}
\hline Gene & Primer sequence & Accession number & Product size (bp) \\
\hline CRP & 5'-TTGGTGGGAGACATTGGAGA-3' & NM_017096.3 & 99 \\
& 5'-AACATTGGGGCTGAATACCCTAC-3' & & 145 \\
IL-6 & 5'-GATTGTATGAACAGCGATGATGC-3' & NM_012589.2 & \\
& 5'-AGAAACGGAACTCCAGAAGACC-3' & & 76 \\
IL-1 $\beta$ & 5'-CCCAACTGGTACATCAGCACCTCTC-3' & NM_031512.2 & \\
& 5'-CTATGTCCCGACCATTGCTG-3' & & 138 \\
GAPDH & 5'-TGGAGTCTACTGGCGTCTT-3' & XM_017593963.1 & \\
& 5'-TGTCATATTTCTCGTGGTTCA-3' & & \\
\hline
\end{tabular}




\section{Cellular Physiology Cell Physiol Biochem 2018;47:266-278 \begin{tabular}{c|c} 
DOI: 10.1159/000489805 & Ond Biochemistry \\
Published online: May 17, 2018 & $\begin{array}{l}\text { 2018 The Author(s). Published by S. Karger AG, Basel } \\
\text { www.karger.com/cpb }\end{array}$
\end{tabular} \\ $\mathrm{Xu}$ et al.: FPA Induces CRP Expression in VSMCs}

tion), anti-p38 (1:1000 dilution) or anti-phospho-p38 (1:500 dilution), anti-ERK1/2 (1:1000 dilution) or anti-phospho-ERK1/2 (1:800 dilution), anti NF-кB p65 (1:800 dilution) or anti-lamin B (1:2000 dilution) antibodies at $4{ }^{\circ} \mathrm{C}$ overnight. After washed three times, the membranes were incubated with the relevant second antibodies (1:3000 dilution) for $1.5 \mathrm{~h}$ and then the immune complexes were enhanced by chemiluminescence.

Enzyme-linked immunosorbent assay (ELISA)

VSMCs were cultured in 96-well plate and stimulated with $10^{-3}-1.0 \mu \mathrm{M}$ FPA for $12 \mathrm{~h}$ or with $10^{-2} \mu \mathrm{M} \mathrm{FPA}$ for the indicated time. Then, the supernatant was collected for assaying levels of IL-1 $\beta$ and IL- 6 by ELISA kit specific for rat IL-1 $\beta$ and IL-6.

\section{Neutralizing experiment}

VSMCs were pretreated with anti-IL-1 $\beta$ and anti-IL- 6 neutralizing antibodies $(5 \mu \mathrm{g} / \mathrm{ml})$ alone or in combination for $1 \mathrm{~h}$ and then stimulated with FPA $\left(10^{-2} \mu \mathrm{M}\right)$ for additional $12 \mathrm{~h}$. Finally, CRP protein expression was detected by western blot.

Determination of CRP expression in VSMCs and in the vessel wall with the immunofluorescence staining

In the in vitro experiment, VSMCs were incubated with the primary mouse anti-smooth muscle-actin antibody and with the secondary cy3 conjugated antibody for the identification of VSMCs after the cells were fixed and blocked. Next, the cells were treated with the primary rabbit anti-CRP antibody and with the secondary Alexa fluor 488 conjugated antibody for the staining of CRP. Subsequently, the cells were stained in the 2-(4-amidinophenyl)-6-indolecarbamidine dihydrochloride (DAPI) solution. Each step above was followed by washing three times. Finally, the cells on the coverslips were preserved in anti-fade mounting medium and CRP expression was observed under fluorescent microscope (Olympus Tokyo, Japan).

In the in vivo experiment, the aortic artery was immediately isolated after blood samples were collected. Frozen sections ( $5 \mu \mathrm{m}$ ) were incubated with rabbit anti-CRP antibody (1:50 dilution) and mouse anti-smooth muscle actin antibody (1:100 dilution) at $4^{\circ} \mathrm{C}$ overnight. After washed three times, the sections were incubated with goat anti-rabbit IgG (Alexa Fluor 488 conjugated) and goat anti-mouse IgG (Cy3 conjugated) antibodies for $30 \mathrm{~min}$ at $37{ }^{\circ} \mathrm{C}$ followed by the DAPI $(10 \mathrm{mg} / \mathrm{ml})$ staining for $3 \mathrm{~min}$ at $37^{\circ} \mathrm{C}$. Finally, the sections were observed under fluorescence microscope (Olympus, Tokyo, Japan).

\section{Measurement of superoxide anion generation in VSMCs}

VSMCs were exposed to FPA $\left(10^{-2} \mu \mathrm{M}\right)$ for $3 \mathrm{~h}$ after the pretreatment with NAC $\left(10^{4} \mu \mathrm{M}\right)$, TTFA $(10$ $\mu \mathrm{M})$, DPI $(10 \mu \mathrm{M})$ for $1 \mathrm{~h}$. Then, the cells were loaded with $\mathrm{H}_{2}$ DCF-DA $(10 \mu \mathrm{M})$ for $1 \mathrm{~h}$ and washed with PBS three times. Fluorescence images were acquired at the excitation wavelength of $488 \mathrm{~nm}$ and the emission wavelength of $525 \mathrm{~nm}$ with fluorescence microscope (Olympus, Tokyo, Japan). Fluorescence intensity was measured and analyzed from the fluorescence images with the Image-pro plus software (Version X; Media Cybernetics, Silver Springs, MD, USA). The relative fluorescence intensity was taken as the average of values from six repeated experiments.

\section{Assay of NF- $\kappa B$ activation in VSMCs by the immunofluorescence staining}

VSMCs were incubated with the primary rabbit anti-NF- $\mathrm{KB}$ p65 antibody at $4^{\circ} \mathrm{C}$ overnight, and then with the secondary Cy3-labeled antibody for $3 \mathrm{~h}$ at $37^{\circ} \mathrm{C}$. The cells were stained in DAPI $(10 \mathrm{mg} / \mathrm{ml})$ for $3 \mathrm{~min}$ at $37^{\circ} \mathrm{C}$. Finally, the cells on the coverslips were preserved in anti-fade mounting medium, and the activated NF-KB subunit p65 was observed under fluorescent microscope (Olympus, Tokyo, Japan).

\section{Animal model}

To observe whether FPA induces CRP generation in vascular smooth muscle tissue in vivo, a model of rat with the high level of blood FPA was established. Male SD rats ( $n=16$, weight: $180-220 \mathrm{~g}$ ) were randomly assigned to the model and control groups [32,33]. The rats in the model group were subcutaneously delivered with $17.0 \mu \mathrm{g} / \mathrm{kg} / \mathrm{h}$ FPA (dissolved in normal saline) for 14 days through the implanted osmotic mini-pumps (Model 2004, ALZET, Cupertino, CA, USA). Rats in control group received normal saline in the same way as the model group. At the end of the experiment, rats were sacrificed under the deep anesthesia with chloral hydrate. Blood samples were collected via the abdominal aorta for measuring plasma FPA and 
CRP levels with ELISA. Then, the thoracic aorta of rats was removed for detecting expressions of CRP, p38, p-p38, ERK1/2 and p-ERK1/2 by western blot and the immunofluorescence staining. All rats were provided by the Experimental Animal Center of Xi'an Jiaotong University School of Medicine. Rats had free access to food and water, and were maintained in a constant environment with a conventional $12 \mathrm{~h} / 12 \mathrm{~h}$ light/dark cycle.

\section{Statistical analysis}

Data were shown as means \pm SEM. Statistical significance between two groups was tested by Student's t test. Statistical significance between multiple groups was assessed by one-way ANOVA followed by Tukey's test. All statistical analyses were performed by the GraphPad Prism (Version 6; La Jolla, CA, USA). $\mathrm{p}<0.05$ was considered to be statistically significant.

\section{Results}

\section{Effect of FPA on the viability of VSMCS}

Fig. 2A showed that FPA from $10^{-4} \mu \mathrm{M}$ to $1.0 \mu \mathrm{M}$ did not produce a significant effect on the viability of VSMCs. Similarly, incubation of VSMCs with $10^{-2} \mu \mathrm{M}$ FPA for 6 to $24 \mathrm{~h}$ did not affect the viability of VSMCs (Fig. 2B).

\section{FPA stimulates CRP expression in VSMCs}

The results in Fig. 3 displayed that stimulation of VSMCs with FPA at $10^{-2}$ to 1.0 $\mu \mathrm{M}$ for $12 \mathrm{~h}$ increased mRNA and protein expression of CRP in VSMCs in a concentrationdependent manner (Fig. 3A and 3B). Incubation of VSMCs with $10^{-2} \mu \mathrm{M}$ FPA for 6 to $24 \mathrm{~h}$ upregulated mRNA and protein expression of CRP in VSMCs in a time-dependent way. Compared with control, mRNA and protein expression of CRP was obviously increased at $6 \mathrm{~h}$ and $12 \mathrm{~h}$ respectively (Fig. 3C and 3D). The immunofluorescence staining showed that there was a weakly positive staining of CRP in control VSMCs. However, treatment of the cells with $10^{-2} \mu \mathrm{M}$ FPA for $12 \mathrm{~h}$ up-regulated CRP expression in VSMCs in comparison with control (Fig. 4).

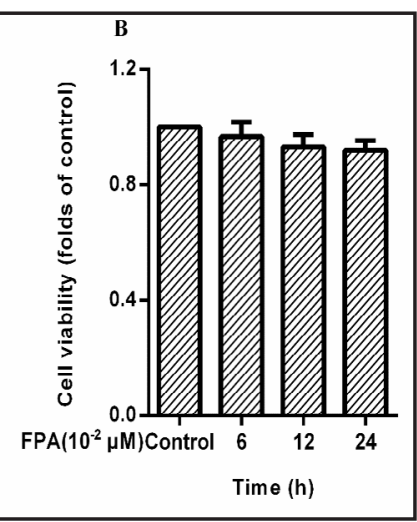

Concentration $(\mu \mathrm{M})$

Time (h)

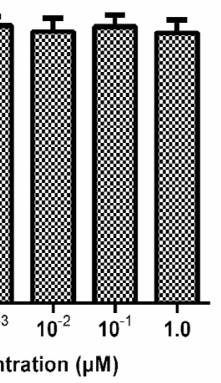

Cs. The cells were incuof FPA for $12 \mathrm{~h}$ or with $10^{-2} \mu \mathrm{M}$ FPA for the indicated time. Then, the cell viability was assayed by the MTT method. Results eight independent experiments were expressed

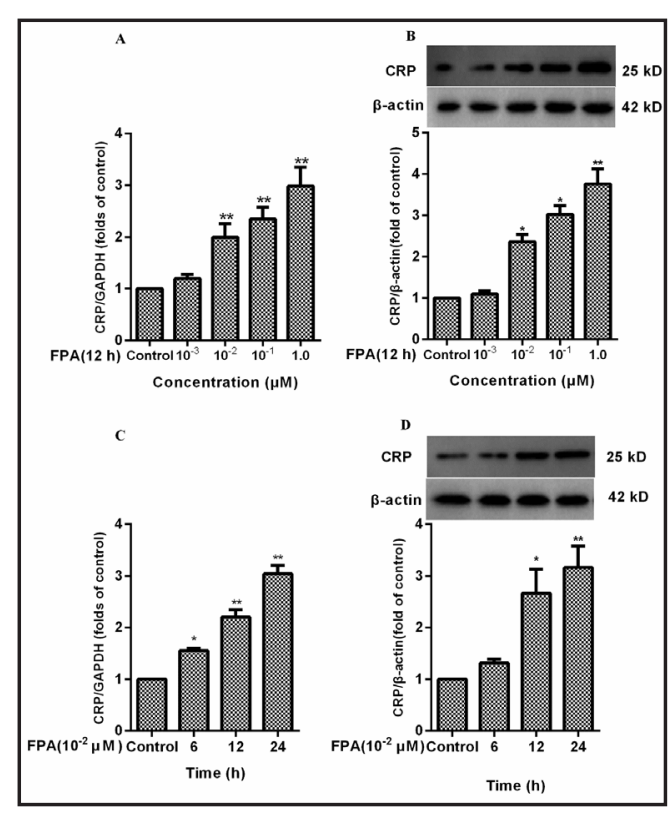

Fig. 3. FPA induces mRNA and protein expression of CRP in VSMCs. The cells were treated with the different concentrations of FPA for $12 \mathrm{~h}$ or with $10^{-2} \mu \mathrm{M}$ FPA for the indicated time. Then, mRNA and protein expression of CRP was identified by quantitative real-time PCR and western bolt, respectively. (A) Concentration-dependent increase of CRP mRNA expression, (B) Concentration-dependent increase of CRP protein expression, (C) Time-dependent increase of CRP mRNA expression, (D) Time-dependent increase of CRP protein expression. Results from three independent experiments were expressed as mean \pm SEM. ${ }^{*} \mathrm{p}<0.05$ and ${ }^{* *} \mathrm{p}<0.01$ vs. control. 


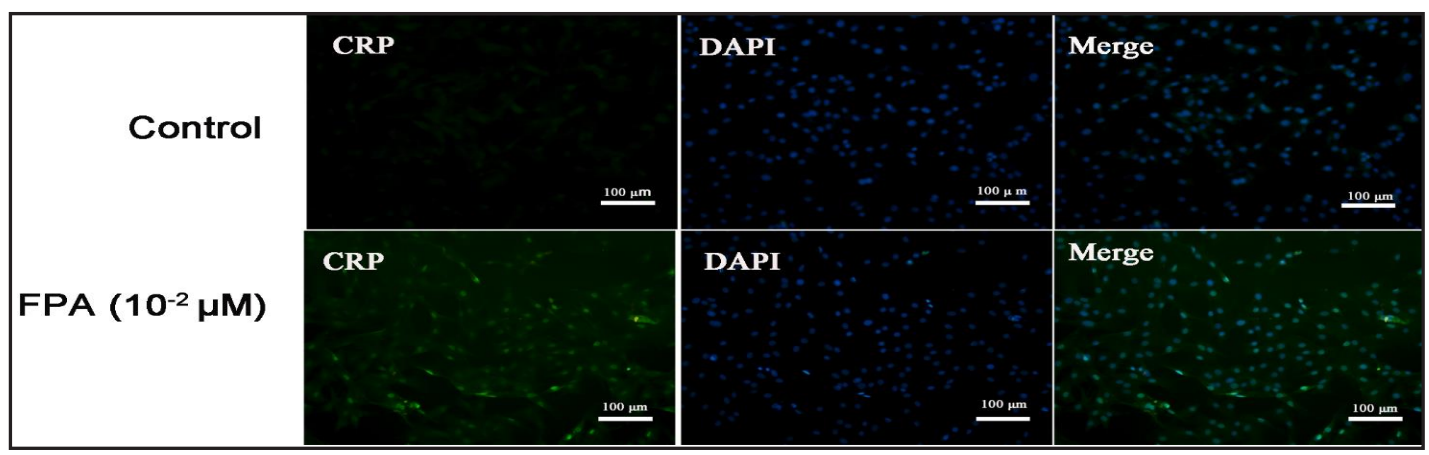

Fig. 4. The immunofluorescence staining of CRP expression in VSMCs (200×). The cells were incubated with $10^{-2} \mu \mathrm{M}$ FPA for $12 \mathrm{~h}$. Then, the fluorescence was observed under fluorescence microscope. The right panels were the merged field of purple color (for cell nucleus) and green (for CRP).

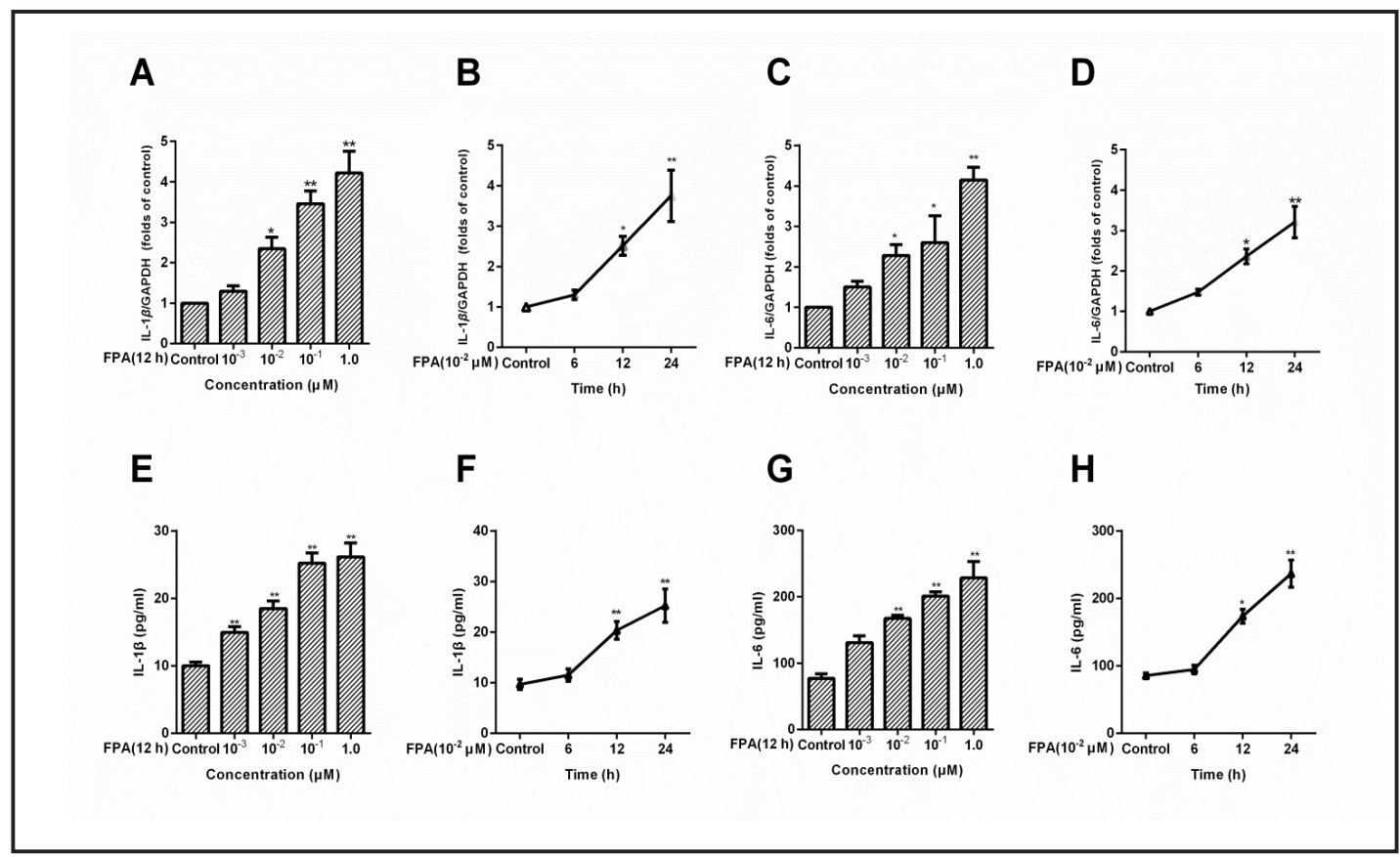

Fig. 5. FPA increases mRNA and protein expressions of IL-1 $\beta$ and IL- 6 in VSMCs. The cells were treated with $10^{-3}-1.0 \mu \mathrm{M}$ FPA for $12 \mathrm{~h}$ or with $10^{-2} \mu \mathrm{M}$ FPA for the indicated times. Then, mRNA and protein expressions of IL-1 $\beta$ and IL- 6 were identified by quantitative real-time PCR and ELISA, respectively. (A) Concentrationdependent increase of IL-1 $\beta$ mRNA expression, (B) Time-dependent increase of IL-1 $\beta$ mRNA expression, (C) Concentration-dependent increase of IL-6 mRNA expression, (D) Time-dependent increase of IL-6 mRNA expression, (E) Concentration-dependent increase of IL-1 $\beta$ protein expression, (F) Time-dependent increase of IL-1 $\beta$ protein expression, $(G)$ Concentration-dependent increase of IL- 6 protein expression, (H) Time-dependent increase of IL-6 protein expression. Results from six independent experiments for ELISA and three independent experiments for quantitative real-time PCR were expressed as mean \pm SEM. ${ }^{*} \mathrm{p}<0.05$ and ${ }^{* *} \mathrm{p}<0.01$ vs. control.

\section{FPA increases $I L-1 \beta$ and $I L-6$ expressions in VSMCS}

In order to further ensure the pro-inflammatory effect of FPA on VSMCs, we observed effect of FPA on the expressions of IL-1 $\beta$ and IL-6 in VSMCs. The results showed that FPA increased both IL-1 $\beta$ and IL- 6 mRNA expressions in VSMCs and IL-1 $\beta$ and IL- 6 levels in the supernatant of the cultured VSMCs in concentration- and time-depended fashions (Fig. 5). 


\section{Cellular Physiology Cell Physiol Biochem 2018;47:266-278 and Biochemistry \begin{tabular}{l|l} 
DOI: 10.1159/000489805 & $\begin{array}{l}\text { (c) } 2018 \text { The Author(s). Published by S. Karger AG, Basel } \\
\text { www.karger.com/cpb }\end{array}$
\end{tabular} Xu et al.: FPA Induces CRP Expression in VSMCs}

Effect of anti-IL-1 $\beta$ and anti-IL-6 neutralizing antibodies on FPA-induced CRP expression in VSMCS

It is known that IL-1 $\beta$ and IL-6 stimulate CRP expression in VSMCs [34], and FPA-induced CRP expression in VSMCs is possibly attributed to the release of IL- $1 \beta$ and IL-6. So, we conducted the neutralizing experiment to identify whether FPA directly induced CRP expression in VSMCs. As shown in Fig. 6, anti-IL-1 $\beta$ and antiIL-6 neutralizing antibodies alone or in combination did not alter FPA-induced expression of CRP in VSMCs. The result suggests that FPA directly induces CRP expression in VSMCs.

ROS are involved in FPA-induced CRP expression in VSMCs

As seen from Fig. 7A, the production of superoxide anion was significantly increased after the incubation of VSMCs with FPA. However, pre-incubation of the cells with TTFA (complex II inhibitor), DPI

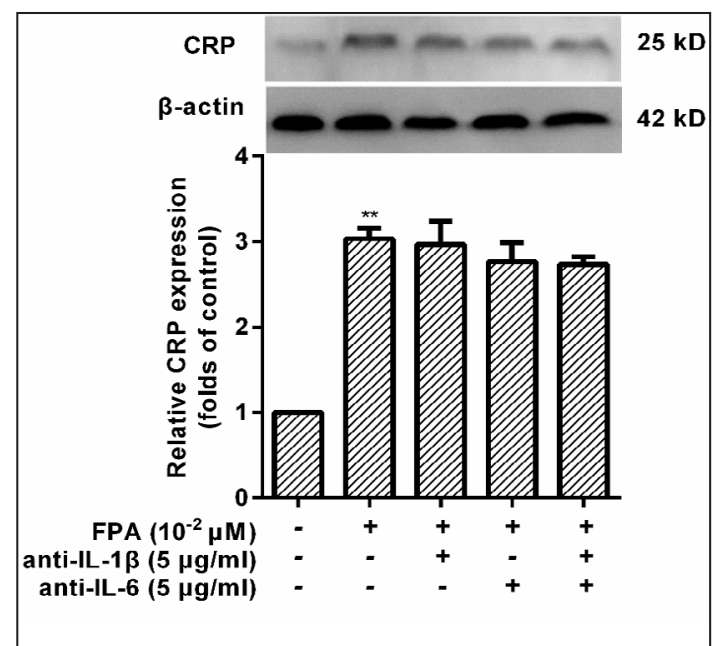

Fig. 6. Effect of anti-IL-1 $\beta$ and anti-IL-6 neutralizing antibodies on FPA-induced CRP expression in VSMCs. The cells were pretreated with anti-IL-1 $\beta$ or/and anti-IL- 6 neutralizing antibodies for $1 \mathrm{~h}$ before the stimulation with FPA for $12 \mathrm{~h}$. Then, CRP protein expression was detected by western blot. Results from three independent experiments were expressed as mean \pm SEM. ${ }^{* *}$ p $<0.01$ vs. control.
(NADPH oxidase inhibitor) and antioxidant NAC reduced FPA-induced production of superoxide anion in VSMCs. The further study indicated that NAC nearly abolished FPA-induced CRP expression in VSMCs (Fig. 7B), suggesting that ROS are involved in FPAinduced CRP expression.

FPA induces CRP expression in VSMCs via ERK1/2/p38 pathway

Fig. $8 \mathrm{~A}$ and $8 \mathrm{~B}$ exhibited that pretreatment of VSMCs with PD98059 (ERK1/2 inhibitor) and SB203580 (p38 inhibitor) weakened FPA-induced expression of CRP. Although JNK inhibitor SP600125 mildly reduced FPA-induced CRP expression, there was no significant statistical difference in CRP expression compared with FPA alone (Fig. 8C), indicating that FPA induces CRP expression in VSMCs via ERK1/2 and p38 pathway.

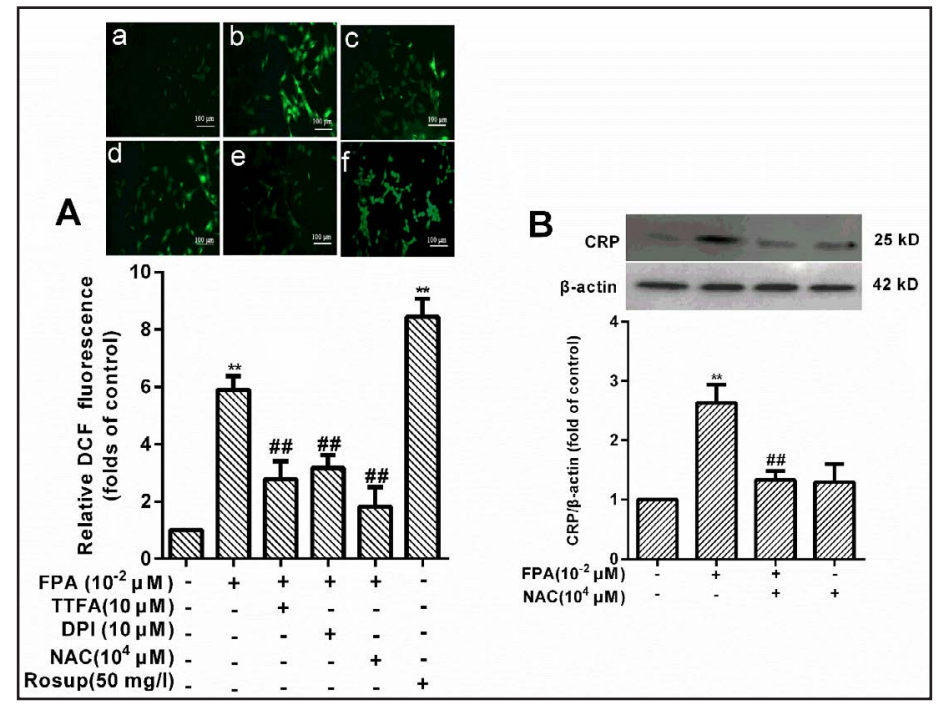

Fig. 7. Involvement of ROS in FPA-induced CRP expression in VSMCs. (A) The cells were exposed to FPA $\left(10^{-2} \mu \mathrm{M}\right)$ for $3 \mathrm{~h}$ after the pretreatment with TTFA $(10 \mu \mathrm{M})$, DPI $(10 \mu \mathrm{M}), \mathrm{NAC}\left(10^{4} \mu \mathrm{M}\right)$. Then, ROS was observed under fluorescence microscope (200×): (a) Control, (b) FPA alone, (c) FPA + TTFA, (d) FPA + DPI, (e) FPA + NAC, (f) Ros up: a positive control. The relative fluorescence intensity was quantified from the fluorescence images. (B) The cells were pretreated with NAC $\left(10^{4} \mu \mathrm{M}\right)$ for $1 \mathrm{~h}$ before the incubation with $10^{-2} \mu \mathrm{M}$ FPA for $12 \mathrm{~h}$ and then, CRP protein expression was detected by western blot. Data from three independent experiments were expressed as mean \pm SEM. ${ }^{* *} \mathrm{p}<0.01$ vs. control, ${ }^{\# \#} \mathrm{p}<0.01$ vs. FPA alone. 


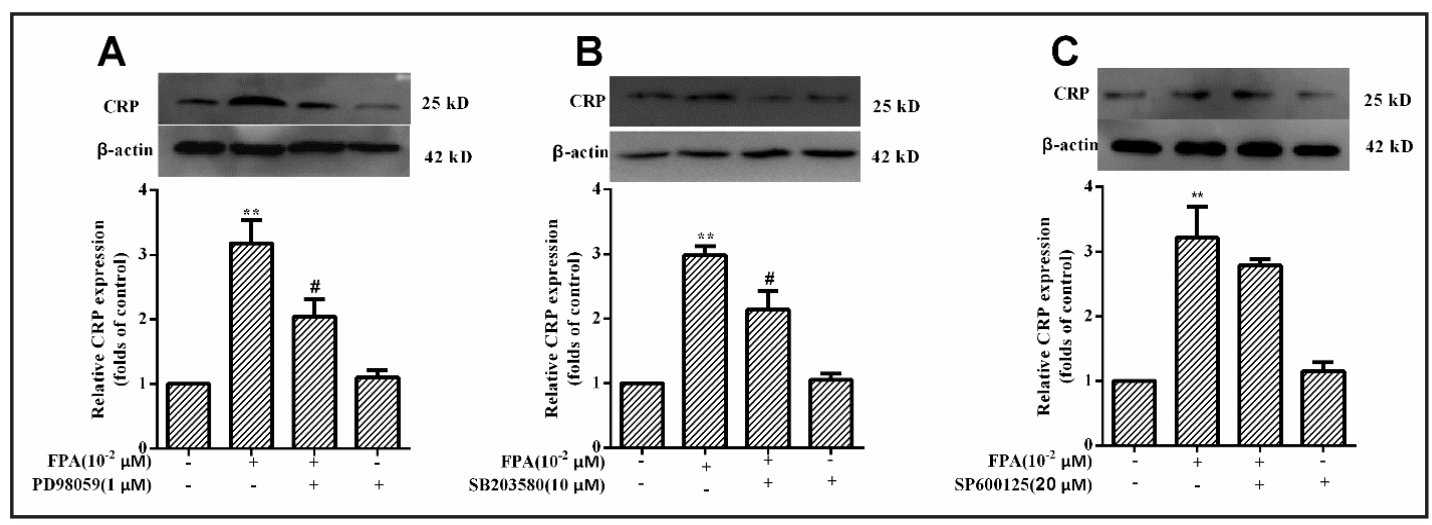

Fig. 8. FPA induces CRP expression in VSMCs via MAPK pathway. The cells were pretreated with SB203580, SP600125 or PD98059 for $1 \mathrm{~h}$ before the incubation with $10^{-2} \mu \mathrm{M}$ FPA for $12 \mathrm{~h}$. Then, CRP protein expression was assayed by western blot. Results from three independent experiments were expressed as mean \pm SEM. ${ }^{* *} \mathrm{p}<0.01$ vs. control, ${ }^{*} \mathrm{p}<0.05$ vs. FPA alone.

FPA induces CRP
expression in VSMCS
through the ROS-
ERK1/2/p38 signal
pathway
In order to clarify the relationship between ROS and ERK1/2/p38 pathways in FPA-induced CRP expression, VSMCs were pretreated with antioxidant NAC, ERK1/2 inhibitor PD98059 or p38 inhibitor SB203580 before stimulated with FPA at $10^{-2} \mu \mathrm{M}$. Then, the phosphorylation of ERK1/2 and p38 was detected. The results showed that FPA activated the phosphorylation of ERK1/2 and p38 in VSMCs, while NAC, PD98059 and SB203580 decreased the expressions of the phosphorylated ERK1/2 and p38. These implicate that FPA induces CRP expression through the ROSERK1/2/p38 signal pathway (Fig. 9).

\section{NF- $\kappa B$ mediates FPA-induced CRP expression in VSMCs}

Western blot analysis showed that FPA enhanced NF- $\kappa B$ level in the nuclei of VSMCs (Fig. $10 \mathrm{~A}$ ). The immunofluorescence staining revealed that fluorescence for the cytosolic NF- $\mathrm{B}$ was stronger in FPA-treated cells than control cells (Fig. 10B), suggesting that more NF- $\kappa$ B is activated in the cytoplasm of VSMCs. The further experiment manifested that pretreatment of VSMCs with NF- $\mathrm{KB}$ inhibitor PDTC reduced FPA-induced expression of CRP (Fig. 10C), verifying NF- $\mathrm{KB}$-mediated CRP expression induced by FPA in VSMCs.

FPA stimulates CRP expression in vascular smooth muscle of rats

The results from the in vivo experiment showed that the subchronic administration of FPA to rats for 14 days obviously increased FPA (Fig. 11A) and CRP concentrations 


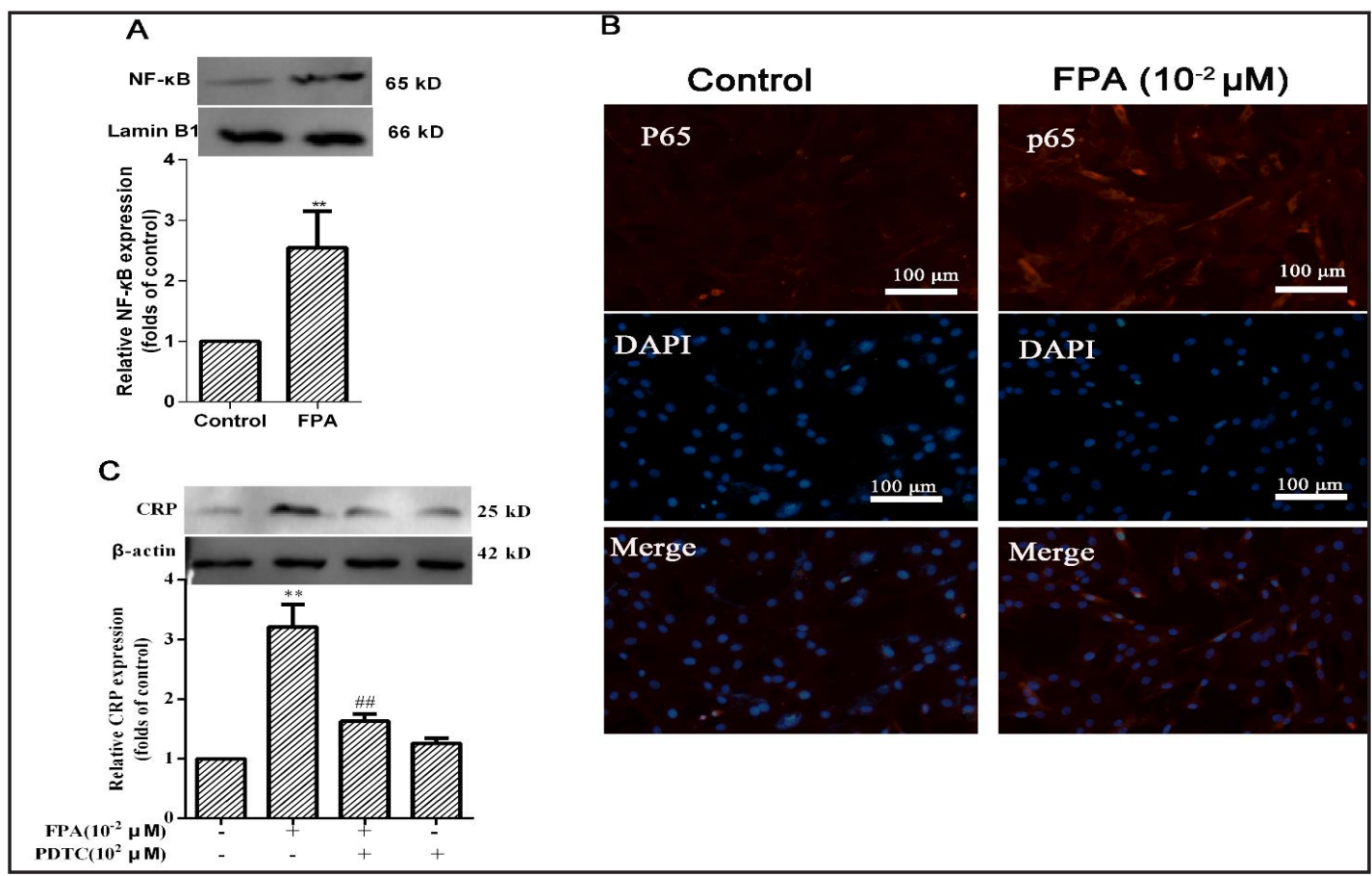

Fig. 10. NF- $\kappa B$ mediates FPA-induced CRP expression in VSMCs. (A) The cells were treated with 10-2 $\mu \mathrm{M}$ FPA for $12 \mathrm{~h}$, and NF- $\kappa B$ level in the nuclei of VSMCs was detected by western blot. (B) The cells were treated with 10-2 $\mu$ M FPA for $12 \mathrm{~h}$ and then, the activated NF- $\kappa B$ subunit $\mathrm{p} 65$ were examined by the Cy3-labeled immunofluorescence staining, and the nuclei were stained by DAPI (200x): (Upper) the activated NF- $\kappa B$ subunit p65 (red), (middle) the cellular nuclei (blue), (below) the merged images. (C) The cells were pretreated with PDTC for $1.5 \mathrm{~h}$ before the incubation with 10-2 $\mu$ M FPA for $12 \mathrm{~h}$, and then CRP protein expression was determined by western blot. Results from three independent experiments were expressed as mean \pm SEM. ${ }^{* *} \mathrm{p}<0.01$ vs. control, \#\#p<0.01 vs. FPA alone.

Fig. 11. FPA stimulates CRP expression in the aortic artery walls of rats in vivo. After the administration of FPA (17 $\mu \mathrm{g} / \mathrm{kg} / \mathrm{h}$ ) to rats for 14 days, plasma FPA and CRP levels were detected by ELISA, and CRP expression in the aortic artery walls of rats was examined with the immunofluorescence staining and western blot. The phosphorylation of ERK1/2 and p38 in the aortic artery walls was detected by western blot. (A) Plasma FPA, (B) Plasma CRP, (C) CRP expression in the aortic artery walls, (D) Expressions of ERK1/2, p-ERK1/2, p38 and p-p38

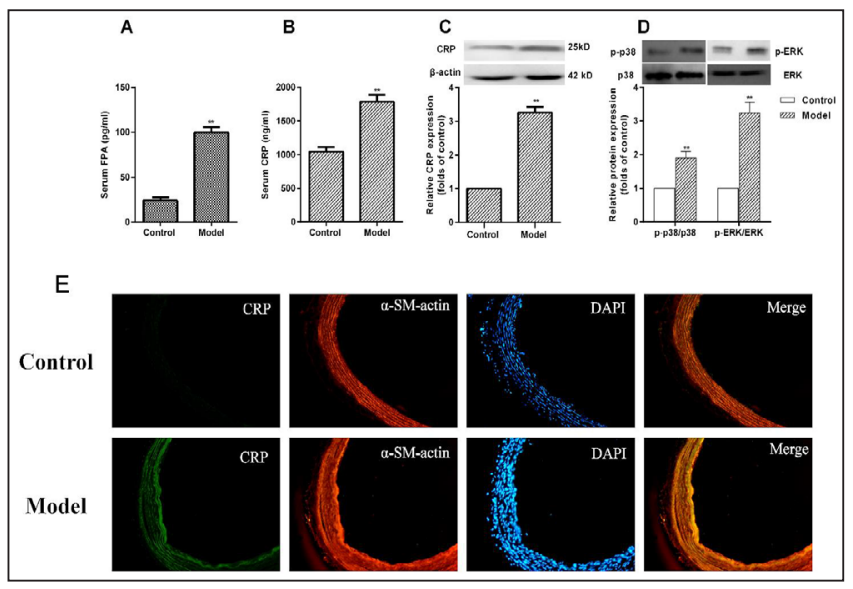
in the aortic artery walls, (E) The immunofluorescence staining of CRP in the vessel wall $(200 \times)$ : The right panels were the merged field of red (for $\alpha$-actin) and green (for CRP), and purple color represented the cell nucleus. Results were expressed as mean $\pm \operatorname{SEM}(n=6) .{ }^{* *} \mathrm{p}<0.01$ vs. model.

in plasma (Fig.11B) and CRP expression in the aortic artery walls of rats (Fig. 11C). The immunohistochemical staining exhibited that a weak staining of CRP existed in the aortic artery walls of control rats. However, CRP expression was potently increased in the aortic artery walls of FPA-treated rats (Fig. 11E). The images of CRP and $\alpha$-actin coexisting KARGER 


\section{Cellular Physiology Cell Physiol Biochem 2018;47:266-278 \\ \begin{tabular}{l|l} 
DOI: 10.1159/000489805 & and Biochemistry \\
Published online: May 17, 2018 & $\begin{array}{l}\text { O 2018 The Author(s). Published by S. Karger AG, Basel } \\
\text { www.karger.com/cpb }\end{array}$
\end{tabular} \\ Xu et al.: FPA Induces CRP Expression in VSMCs}

indicated that VSMCs were a possible origin of CRP (Fig. 11E, merged panels). In addition, FPA enhanced levels of the phosphorylated ERK1/2 and p38 in the aortic artery walls of rats (Fig. 11D).

\section{Discussion}

Atherosclerosis is a common cardiovascular disease and the main pathological basis of the ischemic cardiocerebrovascular diseases. Although the pathogenesis of atherosclerosis is not well defined, more and more evidence supports that atherosclerosis is a chronic inflammatory disease in the artery walls. The inflammation plays an important role in the formation and progression of atherosclerosis. Among the multiple inflammatory factors, CRP is regarded as a representative molecule. The clinical observations find that a high level of FPA in blood means the activation of coagulation system [35] and occurs in the patients with venous thrombosis, pulmonary embolism and ischemic heart disease as a biomarker. However, few reports on the pathological effects of FPA in the cardiovascular system are indexed in literature. Therefore, the present study examined the pro-inflammatory effect of FPA on VSMCs and the molecular mechanisms. The results showed that FPA stimulated mRNA and protein expressions of CRP, IL- $1 \beta$ and IL- 6 in VSMCs in vitro, and anti-IL-1 $\beta$ or anti-IL-6 neutralizing antibody alone or in combination did not change FPA-induced protein expression of CRP in VSMCs. The animal experiment confirmed that the subchronic administration of FPA to rats increased FPA and CRP levels in plasma and CRP expression in the aortic artery walls. These results suggest that FPA is not simply a biomarker of the coagulation activation, but also produces a pro-inflammatory effect on VSMCs by stimulating CRP, IL- $1 \beta$ and IL- 6 expressions.

ROS are both the important second messenger and the direct participant of oxidative stress [36]. Low concentration of ROS is permanently produced in cells, which plays a role as signal molecules. Researches show that ROS participate in the production of many inflammatory cytokines by the different signal pathways such as MAPK and NF-кB $[37,38]$. In the study, we found that FPA stimulated the production of superoxide anion in VSMCs, and the NADPH oxidase inhibitor DPI, mitochondrial respiratory complex II inhibitor TTFA and antioxidant NAC all inhibited FPA-induced the generation of superoxide anion in VSMCs, suggesting that the NADPH oxidase pathway and mitochondria-derived signal pathway are involved in FPA-elicited ROS generation. The abnormal generation of ROS plays important role in CRP expression, and this has been proved in many kinds of cell lines or tissues such as VSMCs [13], endothelial cells [39], liver cells [40] and macrophages [41]. The present study exhibited that antioxidant NAC abolished CRP expression induced by FPA, demonstrating that ROS mediate FPA-induced CRP expression in VSMCs.

MAPK is activated in the inflammatory process of atherosclerosis. ROS are able to regulate MAPK pathway involved in inflammatory process $[42,43]$.The current experiment showed that FPA increased the expressions of phosphorylated ERK1/2 and p38 in vivo and in vitro, and ERK1/2 inhibitor PD98059 and p38 inhibitor SB203580 reduced FPA-induced CRP expression in vitro, implicating that the activated ERK1/2 and p38 participate in FPAinduced CRP production. However, JNK inhibitor SP600125 did not significantly affect FPAinduced CRP expression. In order to understand the roles of ROS in the inflammatory process, we detected the effect of the ROS scavenger NAC on the activation of ERK1/2 and p38. The results show that antioxidant NAC reduced the expressions of the phosphorylated ERK1/2 and p38. Collectively, these confirm that ROS are the upstream molecules of ERK1/2/p38 and regulate ERK1/2/p38 activation, and FPA induces CRP expression via the ROS-ERK1/2/ p38 signal pathway. But, we do not rule out other signal pathways mediating FPA-induced CRP expression, since ERK1/2 and p38 inhibitors partially inhibited FPA-induced CRP expression.

The existed evidence certifies that MAPK may activate NF- $\kappa B$ [44]. NF- $\kappa B$ activation regulates the generation of mediators resulting in the thrombotic potential of human 


\section{Cellular Physiology Cell Physiol Biochem 2018;47:266-278

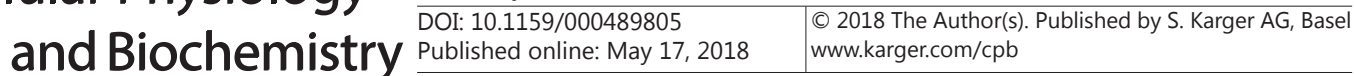 \\ $\mathrm{Xu}$ et al.: FPA Induces CRP Expression in VSMCs}

atherosclerotic plaques, such as tissue factor, matrix metalloproteinases and inflammatory cytokines [45]. The present experiment observed that FPA activated NF- $\kappa B$ and enhanced $\mathrm{NF}-\kappa \mathrm{B}$ level in the nuclei of VSMCs, and the selective NF- $\kappa \mathrm{B}$ inhibitor PDTC reduced FPAinduced expression of CRP. These confirm that NF- $\kappa B$ participates in FPA-induced CRP expression in VSMCs.

In conclusion, the present study demonstrates that FPA induces CRP expression in VSMCs via the ROS-ERK1/2/p38-NF- $\kappa$ B signal pathway. This finding for the first time provides an evidence for pro-inflammatory effect of FPA on VSMCs.

\section{Disclosure Statement}

No conflict of interests exists.

\section{References}

1 Libby P: Inflammation in atherosclerosis. Nature 2002;420:868-874.

2 Paoletti R, Gotto AM, Jr., Hajjar DP: Inflammation in atherosclerosis and implications for therapy. Circulation 2004;109:III20-26.

-3 Ammirati E, Moroni F, Norata GD, Magnoni M, Camici PG: Markers of inflammation associated with plaque progression and instability in patients with carotid atherosclerosis. Mediators Inflamm 2015;2015:718329.

4 Jialal I, Devaraj S, Venugopal SK: C-reactive protein: risk marker or mediator in atherothrombosis. Hypertension 2004;44:6-11.

5 Asanuma Y, Oeser A, Stanley E, Bailey DG, Shintani A, Stein CM: Effects of C-reactive protein and homocysteine on cytokine production: modulation by pravastatin. Arch Drug Inf 2008;1:14-22.

-6 Verma S, Li SH, Badiwala MV, Weisel RD, Fedak PW, Li RK, Dhillon B, Mickle DA: Endothelin antagonism and interleukin-6 inhibition attenuate the proatherogenic effects of C-reactive protein. Circulation 2002;105:1890-1896.

7 Pasceri V, Cheng JS, Willerson JT, Yeh ET: Modulation of C-reactive protein-mediated monocyte chemoattractant protein-1 induction in human endothelial cells by anti-atherosclerosis drugs. Circulation 2001;103:2531-2534.

8 Zwaka TP, Hombach V, Torzewski J: C-reactive protein-mediated low density lipoprotein uptake by macrophages: implications for atherosclerosis. Circulation 2001;103:1194-1197.

-9 Hou J, Xue X, Li J: Vasostatin-2 inhibits cell proliferation and adhesion in vascular smooth muscle cells, which are associated with the progression of atherosclerosis. Biochem Biophys Res Commun 2016;469:948-953.

10 Bennett MR, Sinha S, Owens GK: Vascular smooth muscle cells in atherosclerosis. Circ Res 2016;118:692702.

11 Chen D, Xia M, Hayford C, Tham el L, Semik V, Hurst S, Chen Y, Tam HH, Pan J, Wang Y, Tan X, Lan HY, Shen H, Kakkar VV, Xu Q, McVey JH, Dorling A: Expression of human tissue factor pathway inhibitor on vascular smooth muscle cells inhibits secretion of macrophage migration inhibitory factor and attenuates atherosclerosis in apoE $/$ mice. Circulation 2015;131:1350-1360.

12 Rudijanto A: The role of vascular smooth muscle cells on the pathogenesis of atherosclerosis. Acta Med Indones 2007;39:86-93.

13 Kang DH, Park SK, Lee IK, Johnson RJ: Uric acid-induced C-reactive protein expression: implication on cell proliferation and nitric oxide production of human vascular cells. J Am Soc Nephrol 2005;16:3553-3562.

14 Pang X, Liu J, Zhao J, Mao J, Zhang X, Feng L, Han C, Li M, Wang S, Wu D: Homocysteine induces the expression of C-reactive protein via NMDAr-ROS-MAPK-NF- $\mathrm{BB}$ signal pathway in rat vascular smooth muscle cells. Atherosclerosis 2014;236:73-81.

15 Dosa E, Rugonfalvi-Kiss S, Prohaszka Z, Szabo A, Karadi I, Selmeci L, Romics L, Fust G, Acsady G, Entz L: Marked decrease in the levels of two inflammatory markers, hs-C-reactive protein and fibrinogen in patients with severe carotid atherosclerosis after eversion carotid endarterectomy. Inflamm Res 2004;53:631-635. 


\section{Cellular Physiology Cell Physiol Biochem 2018;47:266-278

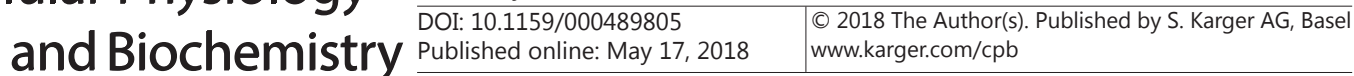 \\ Xu et al.: FPA Induces CRP Expression in VSMCs}

-16 Eidelman RS, Hennekens CH: Fibrinogen: a predictor of stroke and marker of atherosclerosis. Eur Heart J 2003;24:499-500.

-17 Guo YH, Hernandez I, Isermann B, Kang TB, Medved L, Sood R, Kerschen EJ, Holyst T, Mosesson MW, Weiler H: Caveolin-1-dependent apoptosis induced by fibrin degradation products. Blood 2009;113:4431-4439.

$\checkmark 18$ Paramo JA, Rodriguez JA, Orbe J: Fibrinogen. An old hemostatic protein with a new function: non-invasive marker of subclinical atherosclerosis. Med Clin (Barc) 2005;124:790-794.

-19 Yakovlev S, Zhang L, Ugarova T, Medved L: Interaction of fibrin(ogen) with leukocyte receptor alpha M beta 2 (Mac-1): further characterization and identification of a novel binding region within the central domain of the fibrinogen gamma-module. Biochemistry 2005;44:617-626.

-20 Profumo A, Turci M, Damonte G, Ferri F, Magatti D, Cardinali B, Cuniberti C, Rocco M: Kinetics of fibrinopeptide release by thrombin as a function of $\mathrm{CaCl} 2$ concentration: different susceptibility of FPA and FPB and evidence for a fibrinogen isoform-specific effect at physiological $\mathrm{Ca}^{2+}$ concentration. Biochemistry 2003;42:12335-12348.

-21 Eisenberg PR, Sherman LA, Schectman K, Perez J, Sobel BE, Jaffe AS: Fibrinopeptide A: a marker of acute coronary thrombosis. Circulation 1985;71:912-918.

-22 Aleman-Gomez JA, Lopez-Candalez A, Freytes CO, Mignucci M, Linares E: Usefulness of single fibrinopeptide A determination in patients with acute ischemic coronary artery syndromes. Bol Asoc Med P R 1992;84:134-138.

23 Miller GJ, Bauer KA, Barzegar S, Cooper JA, Rosenberg RD: Increased activation of the haemostatic system in men at high risk of fatal coronary heart disease. Thromb Haemost 1996;75:767-771.

24 Hu Y, Song S, Wei W, Liu Z, Tu Y, Zhang J: Study on the hypercoagulable state in patients with angina and myocardial infarction. J Tongji Med Univ 1998;18:18-20, 24.

25 Elmas E, Kaelsch T, Wolpert C, Sueselbeck T, Bertsch T, Dempfle CE, Borggrefe M: Assessment of markers of thrombin generation in patients with acute myocardial infarction complicated by ventricular fibrillation. Clin Cardiol 2006;29:165-169.

26 Morris TA, Marsh JJ, Burrows CM, Chiles PG, Konopka RG, Pedersen CA: Urine and plasma levels of fibrinopeptide B in patients with deep vein thrombosis and pulmonary embolism. Thromb Res 2003;110:159-165.

27 An J, Li A, Yang Z: The effect of burn serm, fibrinopeptide A or B on endothelial cells. J Third Mil Med Univ 1990;12:275-281.

28 Matsuura T, Sato M, Nagai K, Sato T, Arito M, Omoteyama K, Suematsu N, Okamoto K, Kato T, Soma Y, Kurokawa MS: Serum peptides as putative modulators of inflammation in psoriasis. J Dermatol Sci 2017;87:36-49.

29 Persson K, Russell W, Morgelin M, Herwald H: The conversion of fibrinogen to fibrin at the surface of curliated Escherichia coli bacteria leads to the generation of proinflammatory fibrinopeptides. J Biol Chem 2003;278:31884-31890.

-30 Ramos K, Cox LR: Primary cultures of rat aortic endothelial and smooth muscle cells: I. An in vitro model to study xenobiotic-induced vascular cytotoxicity. In vitro Cell Dev Biol 1987;23:288-296.

31 Xu X, He M, Liu T, Zeng Y, Zhang W: Effect of salusin-beta on peroxisome proliferator-activated receptor gamma gene expression in vascular smooth muscle cells and its possible mechanism. Cell Physiol Biochem 2015;36:2466-2479.

-32 Unniappan S, McIntosh CH, Demuth HU, Heiser U, Wolf R, Kieffer TJ: Effects of dipeptidyl peptidase IV on the satiety actions of peptide YY. Diabetologia 2006;49:1915-1923.

-33 van Esch JH, van Veghel R, Garrelds IM, Leijten F, Bouhuizen AM, Danser AH: Handle region peptide counteracts the beneficial effects of the Renin inhibitor aliskiren in spontaneously hypertensive rats. Hypertension 2011;57:852-858.

-34 Zhang X, Liu J, Pang X, Zhao J, Wang S, Wu D: Aldosterone induces C-reactive protein expression via MRROS-MAPK-NF-кB signal pathway in rat vascular smooth muscle cells. Mol Cell Endocrinol 2014;395:61-68.

35 Omarov TI, Sultanov GA, Ragimov VS: A role of D-dimer and fibrinopeptide A in diagnosis of a hemostasis system disorders. Klin Khir 2012;39-41.

36 Rozentsvit A, Vinokur K, Samuel S, Li Y, Gerdes AM, Carrillo-Sepulveda MA: Ellagic Acid Reduces High Glucose-Induced Vascular Oxidative Stress Through ERK1/2/NOX4 Signaling Pathway. Cell Physiol Biochem 2017;44:1174-1187. 


\section{Cellular Physiology Cell Physiol Biochem 2018;47:266-278

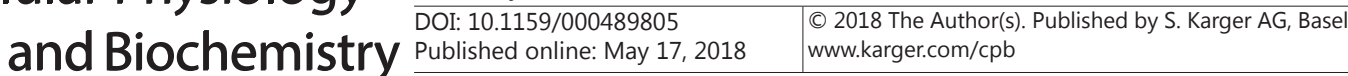 \\ $\mathrm{Xu}$ et al.: FPA Induces CRP Expression in VSMCs}

37 Mendez-Samperio P, Perez A, Alba L: Reactive oxygen species-activated p38/ERK 1/2 MAPK signaling pathway in the Mycobacterium bovis bacillus Calmette Guerin (BCG)-induced CCL2 secretion in human monocytic cell line THP-1. Arch Med Res 2010;41:579-585.

38 Sindhu S, Akhter N, Kochumon S, Thomas R, Wilson A, Shenouda S, Tuomilehto J, Ahmad R: Increased Expression of the Innate Immune Receptor TLR10 in Obesity and Type-2 Diabetes: Association with ROSMediated Oxidative Stress. Cell Physiol Biochem 2018;45:572-590.

39 Han C, Liu J, Liu X, Li M: Angiotensin II induces C-reactive protein expression through ERK1/2 and JNK signaling in human aortic endothelial cells. Atherosclerosis 2010;212:206-212.

-40 Zhao J, Liu J, Pang X, Wang S, Wu D, Zhang X, Feng L: Angiotensin II Induces C-Reactive Protein Expression via AT1-ROS-MAPK-NF-kappa B Signal Pathway in Hepatocytes. Cell Physiol Biochem 2013;32:569-580.

41 Li M, Liu J, Han C, Wang B, Pang X, Mao J: Angiotensin II Induces the Expression of C-reactive Protein via MAPK-Dependent Signal Pathway in U937 Macrophages. Cell Physiol Biochem 2011;27:63-70.

-42 Hu Y, Sun B, Liu K, Yan M, Zhang Y, Miao C, Ren L: Icariin attenuates high-cholesterol diet induced atherosclerosis in rats by inhibition of inflammatory response and p38 MAPK signaling pathway. Inflammation 2016;39:228-236.

43 Yang L, Chu Y, Wang Y, Zhao X, Xu W, Zhang P, Liu X, Dong S, He W, Gao C: siRNA-mediated silencing of Wnt5a regulates inflammatory responses in atherosclerosis through the MAPK/NF-kappaB pathways. Int J Mol Med 2014;34:1147-1152.

44 Xu ZR, Li JY, Dong XW, Tan ZJ, Wu WZ, Xie QM, Yang YM: Apple polyphenols decrease atherosclerosis and hepatic steatosis in apoE ${ }^{-/-}$mice through the ROS/MAPK/NF-kappaB pathway. Nutrients 2015;7:70857105.

45 Pamukcu B, Lip GY, Shantsila E: The nuclear factor-kappa B pathway in atherosclerosis: a potential therapeutic target for atherothrombotic vascular disease. Thromb Res 2011;128:117-123. 